\title{
Prevalence of overweight and obesity among children aged 6-12 years in Dodoma and Kinondoni Municipalities, Tanzania
}

\author{
T.C.E. MOSHA* and S. FUNGO \\ Department of Food Science and Nutrition, Sokoine University of Agriculture, P.O. Box 3109, Morogoro, \\ Tanzania
}

Abstract: A cross-sectional comparison study was conducted to determine the prevalence of overweight and obesity among schoolchildren428 children aged 6-12 years in Dodoma and Kinondoni municipalities in Tanzania. Anthropometric and body composition measurements were taken for all respondents. A total of 428 children were involved in the study. The prevalence of obesity among children aged 6-9 years in Dodoma and Kinondoni were 5.6\% $(n=118)$ and $6.3 \%(n=$ $87)$, respectively. Likewise, $4.2 \%(n=118)$ of children aged $6-9$ years in Dodoma were overweight while $8.6 \%(n=87)$ of their counterparts in Kinondoni municipality were overweight. For children aged $10-12$ years, $3.9 \%(n=118)$ in Dodoma were obese compared to $5.8 \%(n=87)$ of their peers in Kinondoni. Some $4.9 \%$ of the children aged 10-12 years in Dodoma were overweight compared to $5.8 \%$ of their counterparts in Kinondoni. The average body fat mass of children aged $6-9$ years in Dodoma ranged from 21.42-21.81\%, while that of their peers in Kinondoni ranged from $21.66-21.98 \%$. The average body fat mass of children aged 10-12 years ranged between $23.95-24.10 \%$ in Dodoma and 23.65-24.95\% in Kinondoni. There were gender and age differences in body fat mass distribution, with girls and the older children having significantly $(P \leq 0.05)$ higher proportion of body fat mass. In conclusion, although the prevalence of overweight and obesity among children in this study were lower than those reported elsewhere, there is an imminent danger because the trend of the conditions is rising swiftly with urbanization, changes in lifestyles and socio-economic transition. It is recommended that, children should be educated on good nutrition practices and trained to develop healthy eating behaviours. Parents should encourage lifestyle behaviours that promote high level of physical activities. Physical education and organized sports at schools should be revived.

Keywords: urban, childhood, overweight, obesity, Tanzania

\section{Introduction}

Childhood obesity is currently a major health problem in many countries of the world. Recent statistics show that, $16 \%$ of children 6-11 years old are overweight and that an additional $14.3 \%$ are at high risk of becoming overweight (Pierre et al., 2003). Statistics also show that, prevalence of overweight continues to increase during the school age and adolescent stages (Musaiger, 2004). In Tanzania, prevalence of obesity among men and women in urban areas is estimated to be $30 \%$ and $28.6 \%$, respectively (Mosha et al., 2003). In rural communities, prevalence of obesity among men and women is significantly lower than this. A study conducted in Dar es Salaam by Villamor et al. (2006) to determine prevalence of obesity among women of childbearing age (14-42 years) showed an upward trend from 3.6\% in 1995 to $9.1 \%$ in 2004 .

In children, obesity has serious and dramatic implications for health such as cardiomyopathy, pancreatitis orthopaedic disorders and respiratory disorders (NIH, 2007; WHO, 2003). In the short run, obesity has psycho-social effects on children whereby social isolation and low self-esteem of obese children lead to overwhelming feelings of

\footnotetext{
* Correspondence: Prof. Theobald C.E. Mosha; E-mail: tcemosha@yahoo.com; Tel: +255715-884-024
} 
hopelessness, which in turn lead to depression (Joseph et al., 1996; Bowman \& Russell; 2001). Obese children do less well in schools because of stress and anxiety, which interfere with learning and create a vicious cycle in which the over-growing worry increases the declining academic performance (Joseph et al., 1996; Bowman \& Russell; 2001). Excessive weight gain is a precursor to a wide variety of physiological aberrations that ultimately predispose the subject to morbidity and mortality later in life. Studies have shown that, many adult chronic non-communicable diseases have their origin during childhood (Gill et al., 2000; Pierre et al., 2003).

The aetiology of childhood obesity and subsequent diseases is poorly understood, but is likely to be explained by alterations in the regulation of energy balance between energy expenditure and energy intake. There is evidence suggesting that, reduced energy expenditure may be involved in the aetiology of childhood obesity (Goran, 1998). A study by Epistein \& Nueman (1998) showed that, more than 65\% of children 6-19 years of age eat a lot of fat and half of young people (12-21 years) do not engage in regular physical activities. Changes in lifestyles in which children lead sedentary life lead to a low energy expenditure. Socio-economic conditions have significant effects on the levels of physical activity. Frequent use of cars to facilitate movement rather than walking and lack of aerobic exercises contribute to low energy expenditure (Maletnlema, 2002). Similarly, extensive use of electrical/electronic appliances such as television, video games and radios has made children spend much time watching television, and listening to radio programmes and playing electronic games and sports which make children more inactive (Gortmaker et al., 1996; Robinson, 2001; Denison et al., 2002). Lack of health awareness to both parents and children may also be linked to high prevalence of obesity (Musaiger, 2004).

Published data regarding prevalence of overweight and obesity among children aged 6-12 years in Tanzania is scarce. This study was therefore conducted to determine the prevalence of overweight and obesity among children aged 6-12 years in Dodoma and Kinondoni Municipalities in Tanzania. Specifically, this study aimed at determining and comparing the weight-for-age, height-for-age, weight-for-height, body mass index (BMI) for age, mid-upper arm circumference and body composition of children aged 6-12 years in the two urban communities. It is envisaged that data from this study will be useful for health policy makers, educators and other stakeholders in planning appropriate intervention programmes targeting schoolchildren.

\section{Materials and Methods}

\section{Study areas}

This study was conducted in two municipalities of Dodoma and Kinondoni in Tanzania. Dodoma and Kinondoni were selected because they are fast growing metropolitans with rapidly changing lifestyles, modernization and socio-economic transition. In addition, some of the previous studies have shown high prevalence of overweight and obesity among adults living in two municipalities. Since children, share part of the lifestyles of their parents or guardians, it was logical to determine the prevalence rate of the same problem among children aged $6-12$ years. Dodoma municipality is located in the central part of the country about $500 \mathrm{~km}$ west of Dar es Salaam. The municipality has an area of 2,576 $\mathrm{km}^{2}$ and a total population of 287,200 (URT, 2003). The main occupational activities include agriculture, business, wine processing and arts/crafts. Kinondoni is one of the municipalities forming 
Dar es Salaam City. It has a population of 1,088,567. The main occupational activities in Kinondoni include fishing, business, manufacturing industry and tourism.

\section{Study design and sample size}

A cross-sectional, comparison study involving children was conducted between January and May 2008. All schoolchildren aged 6-12 years, living in the selected areas were eligible for the study. The exclusion criteria were children with physical and mental impairment, those with chronic illnesses such as type 1 diabetes, those who were HIV positive, children in boarding schools and children who were overweight or obese and were already in weight management programmes.

A purposive sampling technique was employed to select the private and public schools. Boys and girls had equal chances of being selected into the sample. By random sampling, six schools were selected from each category, making a total of 12 schools. A representative sample of children was randomly selected from each class. The sample size was determined according to Fischer et al. (1991) using the formula:

$$
\mathrm{n}=\mathrm{Z}^{2} \cdot \mathrm{p} \cdot \mathrm{q} / \mathrm{d}^{2}
$$

Where $\mathrm{n}=$ sample size, $\mathrm{z}=1.96$ for a confidence limit of $95 \%, \mathrm{p}=$ expected prevalence of overweight, $d=$ degree of desired precision (in this study was 0.0425 ) and $q=1-p$.

$$
\mathrm{n}=\left(1.96^{2}\right) \text {. 0.28. }(1-0.28) /\left(0.0425^{2}\right)
$$

Applying the formula using expected overweight prevalence rate of 28\% (Mosha et al., 2003) and degree of desired precision of 0.0425 , the sample size of 428 school children was obtained. Using a random sampling technique (table of random numbers), a total of 36 children were selected from each of the 12 schools. Out of the 428 children in the study sample, 150 were boys (60 were in the age group 6-9 years while 90 were in the age group $10-12$ years) while 278 were girls (143 were in the age group 6-9 years while 135 were in the age group $10-12$ years).

\section{Parents/Guardian interviews}

A structured questionnaire was constructed to collect information from the subjects. The questionnaire had three sections: (i) established raport; (ii) solicited anthropometric information; and (iii) solicited information on body composition information. Before data collection, two research assistants were recruited and trained intensively on the procedures for administering the questionnaire. The pre-tested questionnaire was administered to the study children during the mid-morning recess or during mid-day break in order to avoid disruption of class sessions. Data were collected through face-to-face interview with the respondents.

\section{Anthropometric measurements}

Height was determined by the use of length board. Participants were asked to remove the shoes and step infront of the height board placed on a flat floor with heels, buttocks, shoulders and back of the head touching the wall. While the head was comfortably erect with the lower boarder of the orbit in the horizontal plane and external auditory meatus and the arms hanging at the sides in a natural manner, the height was then measured and recorded to the nearest $0.1 \mathrm{~cm}$. Weight was determined by using a digital weighing scale. Participants were asked to remove shoes and step on a zeroed digital weighing scale (Model H-2004, Hungary). The weight was then measure and recorded to the nearest $0.1 \mathrm{~kg}$. The Mid-Upper-Arm Circumference (MUAC) was determined by using a flexible, non- 
stretchable tape. The circumference was located and measured at the mid-point between the tip of the acromion process of the scapula and olecranon process of the ulna of the left arm, while the respondent's arm was hanging at the side and relaxed. The MUAC was then measured and recorded to the nearest $0.1 \mathrm{~cm}$.

\section{Body composition measurement}

Body fat mass was measured using bioelectrical impedence (BIA) machine (Model BF-350, America) and the body fat mass recorded in percent. Respondent were required to remove shoes and sox and step on the electrodes of the BIA machine containing a drop of saline solution.The BIA machine was zeroed before and after each use. Fat free mass was obtained by substracting body fat mass from $100 \%$ (i.e $100 \%$ - Fat mass).

\section{Data analysis}

The data were compiled, coded and analysed using statistcal package for social science (SPSS) programme version 12.5 (SPSS Inc., 2335 Wacker Drive, Chicago, IL 60606), where means, variances and frequencies were used to describe the various nutrition parameters. Epi Info® programme version 1.0 was used to compute weight-for-age, weight-for-height, height-for-age z-scores and BMI-for-age percentiles, which were used to determine the nutritional status of the children.

\section{Ethical consideration}

Ethical clearance to use human subjects was obtained from the Sokoine University of Agriculture Human Studies Ethics Committee. Permission was sought from the municipal authorities to conduct the study in the selected primary schools. Parents, guardians and teachers signed a consent form to affirm their willingness or willingness of the children under their jurisdiction to participate in the study.

\section{Results}

\section{Socio-economic and demographic characteristics of the parents/caregivers}

Of the 428 parents/guardians, $17.8 \%$ were $\leq 19$ years, $53.0 \%$ were $20-35$ years while $29.2 \%$ were $>35$ years old. Majority of the parents/guardians (82.2\%) were adults above 20 years. Most of the parents/guardians (63.2\%) were married, while 13.2\% were widowed, $13.8 \%$ were divorced or separated and $9.8 \%$ were single. A total of 261 (60.9\%) of the parents/guardians had attained primary school education.

Table 1: Socio-economic characteristics of the students' parents/guardians $(n=428)$

\begin{tabular}{llll}
\hline Characteristic & Response & No. of respondents & \% \\
\hline Occupation & Business & 130 & 30.4 \\
& Farming & 20 & 4.7 \\
& Employed & 180 & 42.0 \\
& Housewife & 76 & 17.8 \\
& Unemployed & 6 & 1.4 \\
Education & Self-employed & 16 & 3.7 \\
& None/Informal & 17 & 4.0 \\
& Primary & 261 & 60.9 \\
& Secondary & 111 & 25.9
\end{tabular}




\begin{tabular}{llll}
\hline & $\begin{array}{l}\text { Post-secondary/Vocational } \\
\text { training }\end{array}$ & 24 & 5.7 \\
& University & 15 & 3.5 \\
Average monthly income (US\$) & $7.50-37.45$ & 42 & 9.7 \\
& $38.20-74.91$ & 125 & 29.3 \\
& $75.66-224.72$ & 158 & 36.8 \\
& $225.47-374.53$ & 71 & 16.7 \\
& $>374.53$ & 32 & 7.5 \\
\hline
\end{tabular}

Majority of the households (62.6\%) had a family size of $3-4$ people. A small proportion of the households $(9.1 \%)$ had family sizes of $1-2$ people, $20.1 \%$ had family sizes of $5-6$ people while only $8.2 \%$ of the households had large families of more than 6 people. Forty-two percent of the parents/guardians were employed and $30.4 \%$ were petty traders/businesswomen. Only $16.7 \%$ of the parents/guardians earned incomes ranging from US\$ 225.47- 374.53 while 7.5\% earned incomes above US\$374.53 ((Table 1). This income distribution indicated that, $39.0 \%$ of the parents/guardians earned incomes that were equivalent or less than the minimum government wage of US\$74.91 per month. The majority of the households $(71.3 \%)$ were headed by men while the rest were headed by females.

\section{Nutritional status of the children}

Generally, prevalence of overweight among both girls and boys in Kinondoni was higher than that of their peers in Dodoma. Conversely, prevalence of obesity among boys in Dodoma was slightly higher $(P>0.05)$ than that of their counterparts in Kinondoni. Prevalence trend for overweight and obesity among girls was similar to that of boys in both municipalities (Table 2). The proportions of obese, overweight, normal weight, mildly, moderately and severely underweight boys aged in Dodoma were 6.3, 3.1, 68.8, 12.5, 9.4 and $0.0 \%$, respectively. The proportion of normal weight boys (6 - 9 years) in Dodoma was higher $(68.8 \%, \mathrm{n}=118)$ than that of boys of the same age group in Kinondoni $(60.8 \%)$. In Dodoma there, were no boys who were severely underweight (Table 2). The percent of obese, overweight, normal, mildly underweight, moderately underweight and severely underweight girls aged 6-9 years in Dodoma were 2.3, 4.7, 75.6, 14.0, 2.3 and 1.2 respectively, while the percent of obese, overweight, normal, mildly, moderately and severely underweight girls aged 6-9 years in Kinondoni municipality were 3.4, 8.5, 62.7, 25.4, 0.0 and 0.0 , respectively. None of the girls in Kinondoni was moderately or severely underweight.

Table 2: Distribution of weight for age z-scores (WAZ) for children aged 6 - 9 years ${ }^{1}$

\begin{tabular}{lllllll}
\hline Location/WAZ inference & $\begin{array}{l}\text { Boys } \\
\text { No. }\end{array}$ & $\mathbf{\%}$ & $\begin{array}{l}\text { Girls } \\
\text { No. }\end{array}$ & $\mathbf{\%}$ & $\begin{array}{l}\text { Overall } \\
\text { No. }\end{array}$ & $\mathbf{\%}$ \\
\hline Dodoma & & & & & & \\
Severe underweight & 0 & 0.0 & 1 & 1.2 & 1 & 0.8 \\
Moderate underweight & 3 & 9.4 & 2 & 2.3 & 5 & 4.2 \\
Mild underweight & 4 & 12.5 & 12 & 14.0 & 16 & 13.6 \\
Normal & 22 & 68.8 & 65 & 75.6 & 87 & 73.7 \\
Overweight & 1 & 3.1 & 4 & 4.7 & 5 & 4.2 \\
Obese & 2 & 6.3 & 2 & 2.3 & 4 & 3.5 \\
Kinondoni & & & & & & \\
Severe underweight & 0 & 0.0 & 0 & 0.0 & 0 & 0.0 \\
Moderate underweight & 2 & 7.1 & 0 & 0.0 & 2 & 2.3
\end{tabular}




$\begin{array}{lllllll}\text { Mild underweight } & 5 & 17.9 & 15 & 25.4 & 20 & 62.1 \\ \text { Normal } & 17 & 60.8 & 37 & 62.7 & 54 & 8.0 \\ \text { Overweight } & 2 & 7.1 & 5 & 8.5 & 7 & 4.6 \\ \text { Obese } & 2 & 7.1 & 2 & 3.4 & 4 & 4.6\end{array}$

${ }^{1}$ Obese $=$ WAZ-score =>+3SD; Overweight $=+2 \mathrm{SD}$-- +3SD; Normal weight $=-1$ SD-- +1.9SD; Mild underweight $=$ $1 \mathrm{SD}$-- -1.9SD; Moderate underweight $=-2 \mathrm{SD}$-- -2.9SD; Severe underweight $=<-3 \mathrm{SD}$.

The percent of obese and overweight girls (6-9 years) in Dodoma were lower (2.3 and 4.7\% respectively) than that of their peers of the same age group in Kinondoni municipality (3.4 and $8.5 \%$, respectively). The percent of normal weight girls (6 - 9 years) in Dodoma was higher $(75.6 \%)$ than that of their peers of the same age group in Kinondoni $(62.7 \%)$. Overall, more children were obese and overweight in Kinondoni (4.6 and 8.0\%, respectively) than in Dodoma (3.5 and 4.2\%, respectively) (Table 2 ).

Generally, the proportions of boys and girls aged 6 - 9 years who were classified as normal (-1SD - +2SD) in Kinondoni were higher than those of boys and girls of the same age group in Dodoma. Prevalence of obesity among boys and girls in Kinondoni was significantly higher $(P \leq 0.05)$ than among girls and boys of the same age group in Dodoma (Table 3). The proportion of boys aged 6 - 9 years who were obese, overweight, normal weight, mildly wasted, moderately wasted and severely wasted in Dodoma municipality were $9.4,0.0,68.8,21.9,0.0$ and $0.0 \%$, respectively. The proportion of boys of the same age group who were obese, overweight, normal weight, mildly wasted, moderately wasted and severely wasted in Kinondoni municipality were 3.6, 7.1, 71.4, 10.7, 7.1 and $0.0 \%$, respectively. The proportion of obese boys aged 6 - 9 years in Kinondoni municipality was lower $(3.6 \%)$ than that of boys of the same age group in Dodoma (9.4\%). Likewise, the proportion of boys 6-9 years who were classified as normal in Kinondoni was slightly higher $(71.4 \%)$ than that of their counterparts in Dodoma (68.8\%). The proportion of boys who were mildly wasted in Kinondoni was lower (10.7\%) than that of their peers in Dodoma $(21.9 \%)$. There were no boys who were overweight or moderately wasted in Dodoma.

Table 3: Distribution of weight for height z-scores (WHZ) for children aged 6 - 9 years

\begin{tabular}{|c|c|c|c|c|c|c|}
\hline Location/WHZ inference & $\begin{array}{l}\text { Boys } \\
\text { No. }\end{array}$ & $\begin{array}{l}\text { Girls } \\
\%\end{array}$ & $\begin{array}{l}\text { Overall } \\
\text { No. }\end{array}$ & $\%$ & No. & $\%$ \\
\hline \multicolumn{7}{|l|}{ Dodoma } \\
\hline Severe underweight & 0 & 0.0 & 1 & 1.2 & 1 & 0.8 \\
\hline Moderate underweight & 0 & 0.0 & 4 & 4.7 & 4 & 3.4 \\
\hline Mild underweight & 7 & 21.9 & 12 & 14.0 & 19 & 16.2 \\
\hline Normal & 22 & 68.8 & 58 & 67.4 & 80 & 67.8 \\
\hline Overweight & 0 & 0.0 & 5 & 5.4 & 5 & 4.2 \\
\hline Obese & 3 & 9.4 & 6 & 7.0 & 9 & 7.6 \\
\hline \multicolumn{7}{|l|}{ Kinondoni } \\
\hline Severe underweight & 0 & 0.0 & 0 & 0.0 & 0 & 0.0 \\
\hline Moderate underweight & 2 & 7.1 & 2 & 3.4 & 4 & 4.6 \\
\hline Mild underweight & 3 & 10.7 & 13 & 22.0 & 16 & 18.4 \\
\hline Normal & 20 & 71.4 & 32 & 54.2 & 52 & 59.8 \\
\hline Overweight & 2 & 7.1 & 6 & 10.2 & 8 & 9.2 \\
\hline Obese & 1 & 3.6 & 6 & 10.2 & 7 & 8.0 \\
\hline
\end{tabular}


The proportion of girls aged 6-9 years who were obese, overweight, normal, mildly wasted, moderately wasted and severely wasted in Dodoma were 7.0, 5.4, 67.4, 14.0, 4.7 and $1.2 \%$, respectively. Conversely, the proportion of girls (6 - 9 years) who were obese, overweight, normal, mildly wasted, moderately wasted and severely wasted in Kinondoni were 10.2, 10.2, 54.2, 22.0, 3.4 and $0.0 \%$, respectively. The proportion of normal weight girls $(6-9$ years) in Kinondoni was lower $(54.2 \%)$ than that of their peers of the same age group in Dodoma (67.4\%). The proportions of mildly and moderately wasted girls (6 - 9 years) in Kinondoni were higher than the proportions of girls of the same age group in Dodoma municipality (Table 3). There were no girls (6 - 9 years) who were severely wasted in Kinondoni while in Dodoma about $1.2 \%$ of the girls in the same age group were severely wasted. Overall, 7.6 and $8.0 \%$ of children (6-9 year) in Dodoma and Kinondoni, respectively were obese while 4.2 and 9.2\% of all children in Dodoma and Kinondoni, respectively were overweight.

Table 4: Distribution of height for age z-scores (HAZ) for children aged 6 - 9 years ${ }^{1}$

\begin{tabular}{|c|c|c|c|c|c|c|}
\hline \multirow[t]{2}{*}{ Location/HAZ inference } & \multicolumn{2}{|c|}{ Boys } & \multicolumn{2}{|c|}{ Girls } & \multicolumn{2}{|c|}{ Overall } \\
\hline & No. & $\%$ & No. & $\%$ & No. & $\%$ \\
\hline \multicolumn{7}{|l|}{ Dodoma } \\
\hline Severe stunting & 0 & 0.0 & 0 & 0.0 & 0 & 0.0 \\
\hline Moderate stunting & 3 & 9.4 & 2 & 2.4 & 5 & 4.3 \\
\hline Mild stunting & 2 & 6.3 & 2 & 2.4 & 4 & 3.4 \\
\hline Normal & 25 & 78.0 & 78 & 92.8 & 103 & 88.8 \\
\hline Over-tall & 2 & 6.3 & 1 & 1.2 & 3 & 2.6 \\
\hline Over tall slender & 0 & 0.0 & 1 & 1.2 & 1 & 0.9 \\
\hline \multicolumn{7}{|l|}{ Kinondoni } \\
\hline Severe stunting & 0 & 0.0 & 0 & 0.0 & 0 & 0.0 \\
\hline Moderate stunting & 2 & 7.4 & 1 & 1.9 & 3 & 3.8 \\
\hline Mild stunting & 1 & 3.7 & 2 & 3.8 & 3 & 3.8 \\
\hline Normal & 20 & 74.1 & 45 & 86.4 & 65 & 82.3 \\
\hline Over-tall & 3 & 11.1 & 2 & 3.8 & 5 & 6.3 \\
\hline Over tall slender & 1 & 3.7 & 2 & 3.8 & 3 & 3.8 \\
\hline
\end{tabular}

About $93 \%(\mathrm{n}=27)$ of girls aged $6-9$ years in Kinondoni and $86.4 \%$ of their counterparts in Dodoma had normal HAZ (Table 4 ). About $6.3 \%$ of boys and $1.2 \%$ of girls in Dodoma were too tall for their age (over-tall) while $11.1 \%$ of boys and $3.8 \%$ of girls in Kinondoni were over-tall. Likewise, $3.7 \%$ of boys and $3.8 \%$ of girls in Kinondoni were slender and over-tall. In Dodoma, none of the boys was classified as over-tall and slender and only $1.2 \%$ of the girls were classified into that category. Overall, $88.8 \%$ of children aged 6-9 years in Dodoma had normal heights for their age (not stunted or over-tall), $2.6 \%$ were over-tall, while $0.9 \%$ were over-tall and slender. Conversely, $82.3 \%$ of children aged 6-9 years in Kinondoni had normal height for their age, $6.3 \%$ were over-tall, while $3.8 \%$ of the children were classified as over-tall and slender. Height-for age is an index that measures the linear growth relative to age. A child whose linear growth is high relative to the age is referred to as over-tall (when the HAZ-score is between $+2 \mathrm{SD}$ and $+3 \mathrm{SD}$ ) or over-tall and slender (when the HAZ-score is above +3SD).

The percent of obese, overweight and healthy weight boys in Dodoma were 3.1, 6.3 and 65.6, respectively, while the percent of obese, overweight and healthy weight boys of the 
same age group in Kinondoni were 5.2, 6.9 and 58.6, respectively. In Dodoma, 3.1\% of the boys were obese while in Kinondoni $5.2 \%$ of boys aged 10-12 years were obese. Likewise, the percent of overweight boys in Kinondoni was slightly higher $(6.9 \%)(P>0.05)$ than that of boys of the same age group in Dodoma (6.3\%). The proportion of girls (10-12 years) in Dodoma municipality who were obese, overweight and healthy were $4.3,4.3$ and $64.3 \%$, respectively, while the proportions of obese, overweight and healthy weight girls in Kinondoni municipality were 6.5, 4.8 and $61.3 \%$, respectively. The percent of obese girls aged 10 - 12 years in Kinondoni was significantly higher $(6.5 \%)(P \leq 0.05)$ than that of girls of the same age group in Dodoma (4.3\%. Likewise, the proportion of overweight girls (10-12 years) in Kinondoni was slightly higher $(4.8 \%)(P>0.05)$ than that of girls of the same age group in Dodoma (4.3\%). The proportion of girls (10 -12 years) who had normal healthy weight in Dodoma was slightly higher $(64.3 \%)(P>0.05)$ than that of girls in Kinondoni (61.3\%). Overall, 3.9 and $4.9 \%$ of children aged 10-12 years in Dodoma were overweight and obese, respectively, while 5.8 and $5.8 \%(n=120)$ of children of the same age group in Kinondoni were overweight and obese, respectively (Table 5).

Table 5: Distribution of body BMI-for-age for children aged $10-12$ years $^{1}$

\begin{tabular}{|c|c|c|c|c|c|c|}
\hline \multirow[t]{2}{*}{ Location/ BMI-for age inference } & \multicolumn{2}{|l|}{ Boys } & \multicolumn{2}{|c|}{ Girls } & \multicolumn{2}{|c|}{ Overall } \\
\hline & No. & $\%$ & No. & $\%$ & No. & $\%$ \\
\hline \multicolumn{7}{|l|}{ Dodoma } \\
\hline Underweight & 8 & 25.0 & 19 & 27.1 & 27 & 26.5 \\
\hline Healthy weight & 21 & 65.6 & 45 & 64.3 & 66 & 64.7 \\
\hline Overweight & 2 & 6.3 & 3 & 4.3 & 5 & 4.9 \\
\hline Obese & 1 & 3.1 & 3 & 4.3 & 4 & 3.9 \\
\hline \multicolumn{7}{|l|}{ Kinondoni } \\
\hline Underweight & 17 & 29.3 & 17 & 27.4 & 34 & 28.4 \\
\hline Healthy weight & 34 & 58.6 & 38 & 61.3 & 72 & 60.0 \\
\hline Overweight & 4 & 6.9 & 3 & 4.8 & 7 & 5.8 \\
\hline Obese & 3 & 5.2 & 4 & 6.5 & 7 & 5.8 \\
\hline
\end{tabular}

The average body fat mass for girls was higher than that of boys for both age groups in both municipalities. Generally, the average body fat free mass was higher in boys than in girls for both age groups in both municipalities (Table 6). The average body fat mass for boys aged 6 - 9 years in Kinondoni was slightly higher $(21.66 \%)$ than that of boys of the same age group in Dodoma (21.42\%). On the other hand, the average body fat mass for boys aged $10-12$ years in Kinondoni was slightly lower $(23.65 \%)$ than that of boys of the same age group in Dodoma (23.95\%). For the girls aged 6-9 years the mean body fat mass distributions were $21.81 \%$ (Dodoma municipality) and $21.98 \%$ (Kinondoni). In addition, the average body fat mass for the older girls aged 10 - 12 years in Dodoma was higher $(24.10 \%)$ than that of girls of the same age group in Kinondoni municipality (24.95\%). For boys of both age groups, average body fat mass ranged from 21.42 to $23.95 \%$. Similarly, the average body fat mass for girls in both age groups ranged from 21.81 to $24.95 \%$, which was also lower than the fat mass of $33 \%$ used as a classic cut-off point for obesity in girls. Overall, both boys and girls aged $10-12$ years had significantly higher $(P \leq 0.05)$ average body fat mass than their younger counterpart aged 6-9 years. 
Table 6: Distribution of average mid-upper arm circumference (MUAC), fat mass and fat free mass of the studied children

\begin{tabular}{|lllll|}
\hline Location/Parameter & $\begin{array}{l}\text { Boys (years) } \\
6-9\end{array}$ & $10-12$ & $\begin{array}{l}\text { Girls (years) } \\
6-9\end{array}$ & $10-12$ \\
\hline Dodoma & & & & \\
MUAC (cm) & 18.50 & 21.56 & 18.72 & 22.44 \\
Fat mass (\%) & 21.42 & 23.95 & 21.81 & 24.10 \\
Fat free mass (\%) & 78.58 & 76.05 & 78.19 & 75.90 \\
Kinondoni & & & & \\
MUAC (cm) & 19.50 & 22.10 & 20.23 & 22.36 \\
Fat mass (\%) & 21.66 & 23.65 & 21.98 & 24.95 \\
Fat free mass (\%) & 78.36 & 76.35 & 78.02 & 75.05 \\
\hline
\end{tabular}

\section{Discussion}

Childhood obesity has reached epidemic proportions in the $21^{\text {st }}$ century with rising rates in both developed and developing countries (WHO, 1998; Wang \& Lobstein, 2006). Lifestyle transition and socio-economic improvement have contributed enormously to the escalating problem of overweight and obesity among children in developing countries (Kaneria et al., 2006). Socio-economic and demographic factors such as parental education level, age and income have been associated with the increasing prevalence of overweight and obesity among children in low-income countries (Kaneria et al., 2006; Jelalian \& Steele, 2009). Majority of parents in this study $(60.9 \%)$ had attained only primary school education while only a few had attained post-secondary vocational training $(5.7 \%)$ or university education (3.5\%). A study conducted in Canada (Donalelle, 2001) showed that, children who lived in communities with high unemployment rates, low family income or low educational levels were at a greater risk of being overweight or obese. Kohrs et al. (1979) reported that, the proportions of adult women and men who were overweight (BMI > 25) were inversely related to household income and education level. Families like those of office employees and the businessmen/women may have high income and could afford to purchase nutritious foods, however, due to low education level in nutrition they may decide to purchase foods that are high in energy and low in essential nutrients. Since all members share the food purchased by the family, children are more likely to be affected by the high fat, high calorie foods than other members of the family. In addition, parents have a strong influence on the nutritional status of their children since they are the food providers and the role models for the children. Parental monitoring reduces the number of less-nutritious food items chosen and the overall amount of energy taken (Klesges, 1991; Jouret et al., 2006). Dietary intake patterns within the family determine the nutritional status of both children and parents. It has been demonstrated that, children of obese parents normally consume a higher proportion of energy from fat than do children with none - obese parents (Clark et al., 2007; Kyung, 2008).

Obesity/overweight has also been reported to run in families, which suggests that, some individuals may be predisposed to this disorder. A family history of overweight or diabetes has a strong influence on the nutritional status of the children (Sardesai, 1997). It has been postulated that, two obese parents have $73 \%$ chance of having an obese child and the family that has one obese and one lean parent has $41.2 \%$ chance of having an obese child. A family with both lean parents has only $9 \%$ chance of having an obese child (Sardesai, 
1997). Obesity status of the biological parents is therefore, a good predictor for the development of obesity/overweight in children (Jackson et al., 2002).

Prevalence of overweight and obesity observed in this study were 5.8 and $6.4 \%$ respectively for children aged 6-9 years, and 4.9 and 5.4\% respectively for children aged 10 12 years. These values were lower than those of children of the same age groups in developed countries (Musaiger, 2004; Pierre et al., 2003). A study by Musaiger (2004) in Eastern Mediterranean region reported the prevalence of overweight among children aged 6-11 years to be $16 \%$, while Pierre et al. (2003) in US reported prevalence of overweight among children aged 6-19 years to be as high as 30\%. In other studies, Wang (2001) reported prevalence of overweight and obesity of 14.3 and $11.1 \%$ in USA, 10.0 and $6.0 \%$ in Russia and 3.4 and $3.6 \%$ in China. Wang \& Lobstein (2006) reported prevalence of obesity from various African countries as follows: Mauritius - 4.0\% (age $0-5$ years), Nigeria - 3.3\% ( $0-6$ years), Rwanda - 2.1\% (0 - 5 years), Senegal - 2.6\% (0 - 5 years), Tanzania - 1.5\% ( $2-5$ years), Uganda - 1.6\% (2 - 5 years), Zambia - 2.2\% (2 - 5 years) and Zimbabwe - $4.2 \%$ ( 0 - 3 years). Obesity prevalence rates from the African countries were lower than those observed from this study, probably due to the fact that, these studies were done more than a decade ago and there has been a fast economic improvement and socio-economic transition in Africa during the same period.

Prevalence of overweight and obesity was higher in Kinondoni than in Dodoma municipality. This disparity in the prevalence of overweight and obesity between the two municipalities could be due to the level of socio-economic transition in which Kinondoni being a bigger city has more fast food avenues and franchises with people who were more economically able to afford the fast foods than in Dodoma. Kaneria et al. (2006) reported a similar phenomenon from a study of school-age children in Delhi and Udaipur.

Gender differences in body fat mass were observed among the children of both age groups. Girls in both age groups had higher average body fat mass than their boy counterparts. The gender differences in percent body fat mass have been reported in other studies (Deurenberg et al., 1991; Mast et al., 1998) and were attributed to the natural distribution of fat between males and females essentially at adolescence stage. Likewise, both boys and girls aged 10-12 years had significantly higher average body fat mass than their younger counterparts aged 6-9 years. This could be due to the facts that, majority of children aged 10-12 years were at pre-adolescent/adolescent stage. This is the stage when children attain a rapid growth spurt, characterized by rapid linear growth and deposition of fat mass. Boys tend to deposit more fat free mass than fat mass while girls tend to deposit more fat mass than fat free mass. In this stage also, many children start getting concerned about their own body images/shapes and often adopt unhealthy food choices and meal practices. Children in this age group, especially girls tend to skip meals, eat very little food and snack on high fat, high sugar foods/drinks (Cresswell, 1994). A study by Harnack et al. (1999) revealed that, beverages are the main contributors of energy intake for children and adolescents. According to Pierre et al. (2003), children's rate of consumption of soft drink has increased over the recent years, and now soft drinks provide about $188 \mathrm{kcal} /$ day on average above the energy intake of non- soft drinks consumers. This in turn increases the risk of becoming overweight or obese.

It was concluded from the study that, although the prevalence of overweight and obesity among boys and girls in the study was lower than that reported elsewhere, there is a looming danger as the prevalence of the epidemic is swiftly rising with urbanization, changes in lifestyles and socio-economic transition. The present study highlights that 
childhood overweight/obesity is an emerging health problem that requires effective preventive strategies to halt the epidemic at its early stages. Factors that contribute to overweight and obesity among children have been widely reported. In addition, since Dodoma and Kinondoni municipalities are fast growing metropolitans, children are being exposed to big city culture, characterized by sedentary lifestyle, high intake of lessnutritious, energy dense snacks/soft drinks and many fast food outlets. It is therefore pertinent to prevent the rising prevalence of obesity and overweight among children since the cost of managing this epidemic is very high considering the low incomes and the large number of competing diseases such as malaria and HIV that must also be addressed. It is recommended that, children should be educated on good nutrition practices and should be trained to develop healthy eating behaviours. Parents should encourage lifestyle behaviours that promote high level of physical activities. Physical education and organized sports at schools should be revived.

\section{Acknowledgements}

The authors acknowledge with thanks the financial support provided by the Belgian Technical Cooperation, Dar es Salaam. We thank the school children, parents, guardians and the teachers for generously accepting to participate in this study. Thanks are also due to the regional and district education authorities in Dodoma and Dar es Salaam for granting us permission to carry out the study in the schools and for providing some logistical support.

Received 17 October 2009

Revised 22 November 2009

Accepted 23 November 2009

\section{References}

Bowman, B.A. \& Russell, R.M. (2001) Present Knowledge in Nutrition. 8th ed. Washington, DC: ILSI Press. Pp 120 - 221.

Clark, H.R., Goyder, E., Bissell, P., Blank, L. \& Peters, J. (2007) How do parent's child feeding behaviors influence child weight? Implications for childhood obesity policy. Journal of Public Health and Medicine 29, 132-217.

Cresswell, J. (1994) Research Design. Qualitative and Quantitative Approaches. SAGE Publication, Thousands Oaks, New Delhi. 228 pp.

Dennison, B.A., Erb, T.A. \& Jenkins, P.L. (2002) Television viewing and television in bedroom associated with overweight risk among low-income pre-school children. Paediatrics 109, 1028 - 1035.

Deurenberg, P., Weststrate, J.A \& Seidel, J.C. (1991) Body mass index as a measure of body fatness: age- and sex-specific prediction formulas. British Medical Journal 65, 105-114.

Donalelle, R. J. (Ed.) (2001) Health Basics. San Francisco institute, USA. 400 pp.

Epistein, F. A. \& Nueman, J. (1998) Defining overweight and obesity. American Journal Clinical Nutrition 72, 1067.

Fischer, A.A., Laing, J.E., Stockel, J.E. \& Townsend, J.W. (1991) Handbook for Family Planning Operations Research Design. Population Council New York. 45pp. 
Gill, P., Baur, L.A., Bauman, A.E. \& Steinbeck, K.S. (2000) Establishing a standard definition for child overweight and obesity worldwide: International survey. British Medical Journal 320, 1240-1243.

Goran, M. I. \& Min, S. (1998) Prevalence of obesity in children. American Journal of Clinical Nutrition 6, $944-949$.

Gortmaker, S.L., Must, A., Sobol, A.M., Peterson, K., Colditz, G.A. \& Dietz, W.H. (1996) Television viewing as a cause of increasing obesity among children in the United States 1996 - 1990. Archives of Pediatric and Adolescent Medicine 150, 356 - 362.

Harnack, L., Stang, J. \& Story, M. (1999) Soft drink consumption among US children and adolescents: nutritional consequences. Journal of the American Dietetic Association 99, 43.

Jackson. A.S., Stanforth, P.R. \& Gagnon, J. (2002) The effect of sex, age and race on estimating percentage body fat from body mass index: the Heritage Family Study. International Journal of Obesity Related Metabolic Disorders 26, 789-796.

Jelalian, E. \& Steele, R.G (2009) Socio-economic Factors Related to Obesity in Children and Adolescents. Clinical Child Psychology Book Series Part III. Springer US. Pp 127 - 143.

Joseph, K., Ang, K., Ngo, K., \& Yim, G. (1996) Obesity in Children, Internet Journal of Health Promotion, URL; http://www.monash.edu.au/health/IJHP/1996/2. Accessed 12 September 2009

Jouret, B., Ahluwalia, N., Dupuy, M., Negre-Pages, L., Grandjean, H. \& Tauber, M. (2007) Factors associated with overweight in preschool-age children in southwestern France. American Journal of Clinical Nutrition 85, 1643-1649.

Kaneria, Y., Sigh, P. \& Sharma, D.C. (2006) Prevalence of overweight and obesity in relation to socio-economic conditions in two different groups of school-age children of Udaipur City (Rajasthan). Journal of Indian Academy of Clinical Medicine 7, 133-135.

Kavishe, F.P. (1993) Nutrition - Relevant Actions in Tanzania. UN ACC/SCN Country Case Study for the XV Congress of the International Union of Nutritional Sciences. Adelaide, September 26 - October 1.

Klesges, R.C., Stein, R.J., Eck, L.H., Isbell, T.R. \& Klesges, L.M. (1991) Parental influence on food selection in young children and its relationship to childhood obesity. American Journal of Clinical Nutrition 53, 859-864.

Kohrs, M.B., Wang, L.L., Eklund, D., Paulsen, B. \& O'Neal, R. (1979) The association of obesity with socio-economic factors in Missouri. American Journal of Clinical Nutrition $32,2120-2128$.

Kyung, R. (2008) Childhood overweight and the relationship between parent behaviors, parenting style and family functioning. The Annals of the American Academy of Political and Social Science 615, 11-37.

Maletnlema, T.N (2002) A Tanzanian perspective on the nutrition transition and its implications for health. Public Health Nutrition 5(1A), 163 - 168.

Mast, M., Kortzinger, I., Konig, E. \& Muller, M.J. (1998) Gender differences in fat mass of 5 7 year old children. International Journal of Obesity 22, 878-884.

Mosha, T.C.E. (2003) Prevalence of obesity and chronic energy deficiency (CED) among females in Morogoro District, Tanzania. Ecology of Food and Nutrition 42, 37 - 67.

Musaiger, O. (2004) Overweight and obesity in the Eastern Mediterranean region. Eastern Mediterranean Health Journal 10, 789.

NIH (2007) Clinical guidelines on the Identification, evaluation, and treatment of overweight and obesity in Adults: Evidence report. National Institute of Health, National Heart, Lung 
and Blood Institute. URL: www.nhlbi.nih.gov/guidelines/obesity/ob-gdlns.htm. Site visited 12.10.2009.

Pierre, I.B., Huang, C.L., Lee, J.Y. \& Lin, B.H. (2005) Dietary habits, demographics and the development of overweight and obesity among children in the United States. Food Policy 30, $115-128$.

Robinson, T.N. (2001) Television viewing and childhood obesity. Paediatric Clinics of North America 48, 1017 - 1025.

Sardesai, V. (1997) Introduction to Clinical Nutrition. Marcel Dekker Inc., New York. 481 pp.

URT (2003) Population and Housing Census General Report. Central Census Office, National Bureau of Statistics, President's Office Planning and Privatization. United Republic of Tanzania. Department of Government Printers, Dar es salaam, Tanzania. pp 102.

Villamor, E., Msamanga, G., Urassa, W., Petraro, P., Spiegelman, D., Hunter, D.J. \& Fawzi, W.W. (2006) Trends in obesity, underweight and wasting among women attending prenatal clinics in urban Tanzania 1995-2004. American Journal of Clinical Nutrition 83, 1387-1394.

Wang, Y. (2001) Cross-sectional comparison of childhood obesity; the epidemic and the relationship between obesity and socio-economic status. International Journal of Epidemiology 30, 1129-1130.

Wang, Y. \& Lobstein, T. (2006) Worldwide trends in childhood overweight and obesity. International Journal of Pediatric Obesity 1, 11-25.

WHO (1998). Obesity-Preventing and Managing the Global Epidemic. World Health Organization, Geneva. Pp 231 - 247.WHO (2003). Obesity and Overweight. World Health Organization, Geneva. 400 pp. 